\title{
GÖRME ENGELLİ BİREYLERİN GÜNLÜK YAŞAMINI KOLAYLAŞTIRMAK ADINA BİR ÖNERME: BRAIILLE ALFABELİ GIYYSILER
}

\author{
Meltem ÖZSAN ${ }^{1 *}$, Feride HASRET ${ }^{1}$ \\ 1İstanbul Gelişim Üniversitesi, Meslek Yüksekokulu, Moda Tasarımı Bölümü, İstanbul, Türkiye
}

\begin{tabular}{|c|c|}
\hline Anahtar Kelimeler & Özet \\
\hline $\begin{array}{l}\text { Görme engelli, } \\
\text { Ergonomi, } \\
\text { Braille, } \\
\text { Giysi, } \\
\text { Tasarım }\end{array}$ & 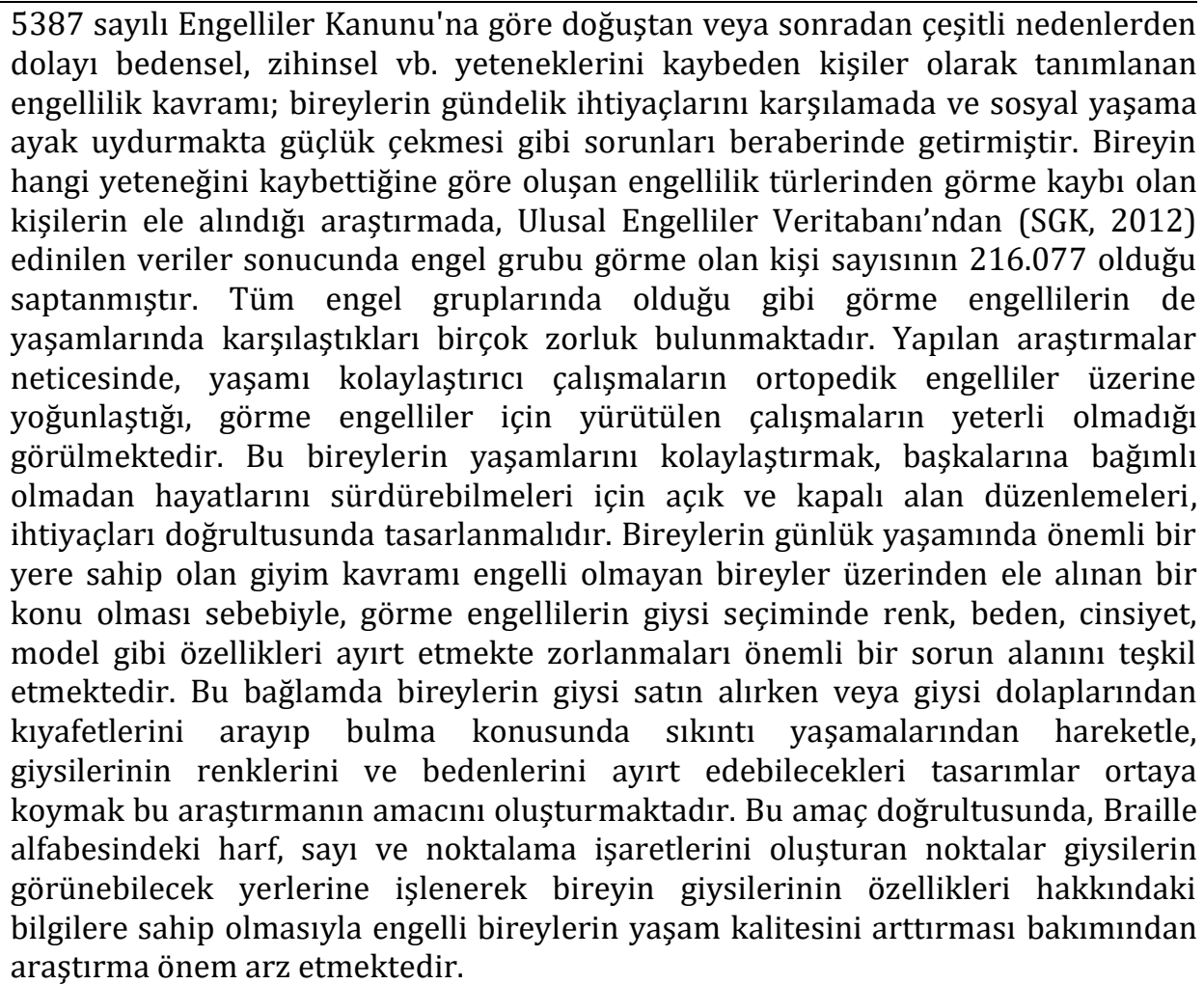 \\
\hline
\end{tabular}

\section{THESIS FOR SIGHT-DISABLED PEOPLE TO EASE THEIR DAILY LIFE: CLOTHES WITH BRAILLE}

\author{
Meltem ÖZSAN ${ }^{1 \dagger}$, Feride HASRET ${ }^{1}$ \\ ${ }^{1}$ İstanbul Gelişim University, Vocational School, Dept. of Fashion Design, İstanbul, Turkey
}

\begin{tabular}{ll}
\hline Keywords & Abstract \\
\hline Sight-disabled, & According to the Disability Law numbered 5387, disability term described as \\
Ergonomics, & people losing their physical, mental, spiritual, emotional, social abilities since from \\
Braille, & birth or because of various reasons, causes problems of meeting daily needs and \\
Clothing, & adapting to social life. Of all the disability groups formed of the person loses which \\
Design, & of his abilities, in the research studying people with vision loss the number of
\end{tabular}

\footnotetext{
* ilgili yazar: mozsan@gelisim.edu.tr

${ }^{\dagger}$ Corresponding author: mozsan@gelisim.edu.tr
} 
people whose disability is vision loss is 216.077 according to data obtained of National Disabilities Database under the Ministry of Family and Social Policies. As seen in all the groups of people with disabilities, there are many challenges people with vision loss face in life. Researches show that works to ease daily life mostly focus on orthopedic disabilities but the works for people with vision loss aren't enough. In order to ease these people's lives and allow them to keep their lives without depending on any other people, indoor and outdoor arrangements should be made according to their needs. Clothing is important when it comes to people without disabilities but for people with vision loss distinguishing color, variety, style, sexuality, models and so on create a major problem. Facing with problems of distinguishing clothes' colors, models, types while purchasing and getting them of their wardrobes, this research's aim is easing these people's lives by helping them distinguish clothes' colors, models and types. For this purpose, information about the clothes is processed over the clothes' visible parts in Braille's letters, numbers, punctuation marks which helps them know the features of clothes and eases the process of disabled people's adaptation to social life. Within this study, views and opinions of people with vision loss have been taken into account and there have been some model suggestions in order to minimize the problems these people face during clothing. That people find their desired dresses over which features of clothes are processed in Braille, in a short time by touching at them and know what color, model of clothes they wear will ease their adaptation to daily life.

\section{Giriş}

Öğrenmede duyu organlarının kullanımı, görme, koklama, işitme, dokunma ve tat alma bireyin herhangi bir konuda bilgi sahibi olması açısından oldukça önem arz etmektedir. Bireyin yeti yitimi sebebiyle oluşacak olan engellilik durumu, diğer duyu organlarının ve hislerinin daha aktif kullanımı ile kişinin kendisini ifade edebilmesine ve öğrenmesine yardımcı olmaktadır. Bu durumda, engellilik durumu görme olan bireylerin, dokunma, işitsel bilgilendirme, tat alma ve koklama duyuları kişinin öğrenme yaklaşımında önemli bir rol üstlenmektedir.

Tüm bireyler yaşama, eğitim, çalışma, sosyal ve kültürel hayata katılma gibi temel haklara sahiptir. Engelli bireylerin sosyal, ekonomik ve toplumsal yaşama katılımının sağlanması ve bağımsız bir yaşam sürdürebilmeleri için çeşitli imkânların sunulması gerekmektedir (Akçall, 2015). Engelli bireylerin sıradan insanlar gibi yaşamlarını bir başkasına ihtiyaç duymadan sürdürebilmesi ve toplumsalsosyal yaşama katılım sağlayabilmesi için gerekli düzenlemeler yapılmalıdır.

Türkiye Özürlüler Araştırması (TÜIK, 2010) verilerine göre; Türkiye nüfusunun \%12,29'unu engelli bireylerin oluşturduğu belirlenmiștir. Toplumdaki çeşitliliği göz önünde bulundurarak bireylerin engellilik durumlarına yönelik ihtiyaçlarını karşllayabilecek uygulamaların gerçekleştirilmesi gerekmektedir. $\mathrm{Bu}$ konuda yapılan hizmetlere bakıldığında, çoğunlukla bedensel engelli grubunun dikkate alındığı, görme engelliler gibi özel materyal ve hizmetlere ihtiyaç duyan engel gruplarına yönelik çalışmaların yetersiz olduğu gözlenmiştir. Ancak, Türkiye' de engelli gruplarının oranlarına bakıldığında, bedensel engellilerin \%8,8'ini, görme engellilerin ise $\% 8,4$ ' ünü oluşturduğu belirlenmiştir
(TÜIK, 2010). Engel grupları oranlarının birbirlerine yakın olması ile her iki engel gruplarına yönelik hizmet ve tasarımların aynı oranda yapılması gerekmektedir.

$\mathrm{Bu}$ düşünceden hareketle bireylerin gündelik yaşamlarında ailelerine veya yakın çevrelerine ihtiyaç duymadan giysilerinin renk, beden gibi özelliklerini dokunma güdüsü ile öğrenerek kendilerinin giysileri içerisinden seçim yapması ve o giysileri kombinleyebilmesi hedeflenmiștir. $\mathrm{Bu}$ şekilde bireyin sosyal yaşam içerisinde duygusal ve bilişsel motivasyonlarının arttırılmasının yanı sıra engeli olmayan insanlara göre basit denilebilecek kadar kolay işlerin, görme engelli bireyler için de basite indirgenmesi ve ikinci bir kişiye bağımlı olarak yaşamını sürdürmek zorunda kalmadan giysi satın alabilme ve giysilerini seçebilme öz yeterliliğini yerine getirebilmesi açısından önem arz etmektedir.

\section{Engellilik Kavramı}

Engellilik, gerek fiziksel gerekse zihinsel işlev bozukluklarıyla, bunların hareket yeteneğinde, tutum ve davranışlarında sebep olduğu eksiklik veya güçlükle tanımlanmaktadır (Arıkan, 2002). Engellilik kavramı bireye bağlı eksiklik olarak görülmemekte, bireyin toplum içerisinde herhangi bir faaliyeti yerine getirmede, toplumun kişiye sunmadığı özel düzenleme ve hizmetlerin eksikliğinden dolayl, kişinin o faaliyeti gerçekleştirmede yaşadığı zorluk olarak ortaya çıkmaktadır. "Bu bağlamda insanları engelli yapanın yeti yitimleri değil, çevresel anlamda kaldırılmayan engeller ve sunulmayan hizmetler olduğu vurgusu dikkat çekmektedir (Goltsman vd., 1993)." 
Türkiye'de 5378 sayılı "Engelliler Hakkında Kanun'un 3. maddesinde engelli ve engellilik durumu olmak üzere ayrı tanımlara yer verilmektedir. Engelli, fiziksel, zihinsel, ruhsal ve duyusal yetilerinde çeşitli düzeyde kayıplarından dolayı topluma diğer bireyler ile birlikte eșit koșullarda tam ve etkin katılımını kısıtlayan tutum ve çevre koşullarından etkilenen birey olarak tanımlanmaktadır. Engellilik durumu ise; bireyin engelliliğini ve engellilikten kaynaklanan özel gereksinimlerini, uluslararası yöntemleri temel alarak belirleyen derecelendirmeler, siniflandirmalar ve tanilamalar olarak ifade edilmektedir (Kanun 5378, 2005).

Goldsmith (1976) tarafından yapılan çalışmada; fiziksel eksiklikleri yüzünden genel ihtiyaçlara göre tasarlanmış binaları kullanımlarında uygun olanakların yokluğundan dolayı engellere uğrayan insanlar olarak tanımlanan engellilik kavramı; bireyin duyusal, bedensel, zihinsel ve ruhsal yetilerinin azalması ve kaybedilmesi değişkenlerini baz alarak engelli sınıflandırılması yapılmaktadır.

\subsection{Görme Engelli Bireyler}

Duyusal engelliler başlığı altında incelenecek olan görme engelliler, görme yetersizliğinden etkilenmiş, ıșık algısı olmayan, yani kör olarak tabir edilen bireyler ile az gören bireyler için kullanılan ortak bir addır. Bireyin görme duyusundaki yeti yitimi oranı dikkate alınarak düzenlenen sınıflandırma; yapılan tüm iyileștirme ve düzeltmeler sonrasında kișinin görüşü 20/200 oranından daha düşük veya görüş alanı 20 dereceden daha düşük ise kör, 20/70 daha düşük ve görüş alanı 20 dereceden daha dar ise kısmen veya az görme olarak belirlenmiştir.

Görme engellilerin toplumsal hayata katılımı ve bilgiye erişiminin sağlanması için gerekli hizmet ve teknolojiler geliştirilmiştir. Görme yetersizliğinden etkilenmiş(az gören) bireyler için metinlerin yazı puntolarının fotokopi araçlarının kullanımıyla büyütülmesi ya da büyüteçlerin kullanılması, bunun yanı sıra yazıyla zemin arasındaki zıtlıkların ayarlanması ile bireyin bilgiye ulaşması desteklenmelidir. Yazılı materyali okuyamayacak kadar görmeyen bireyler için ise 19. yüzyılda kendisi de kör olan Louis Braille tarafından geliştirilmiş, kabartılmış altı nokta Braille sistemi, dokunarak bilgiye ulaşmaları için kullanılmaktadır.

Bu sistem, parmak ucuyla duyumsanacak kabarıklıkta altı nokta soldan sağa iki ve yukarıdan aşağıya üç noktanın oluşturduğu bir dikdörtgen biçimindedir. Karakterleri betimlemede kolaylık sağlamak amacıyla kabartılmış noktalar soldan aşağıya doğru 1., 2., 3. nokta ve sağdan aşağıya doğru 4., 5., 6. nokta olarak sıralanır. Örneğin 1. noktanın, yani soldan 1. noktanın kabartılmış olması "a" harfini, 1. ve 2. noktaların kabartılmış olması "b" harfini, 1. ve 4. noktalar "c" harfini, 1., 4. ve 5. noktalar "d" harfini gösterir (Özyürek, 1998).

$$
\begin{array}{|cccccc|}
\hline \bullet \bullet 4 & \bullet & \bullet & \bullet \bullet & \bullet \bullet & \bullet \\
2 \bullet \bullet 5 & \cdots & \bullet & \cdots & \bullet \bullet & \bullet \\
3 \bullet \bullet 6 & \cdots & \cdots & \cdots & \cdots & \cdots \\
& a & b & c & d & e \\
& 1 . & 1.2 & 1.4 & 1.4 .5 & 1.5 \\
& & & & & \\
\hline
\end{array}
$$

Şekil 1. Braille Harf Örnekleri (Özyürek, 1998)

\begin{tabular}{rccccc|}
\hline$\bullet$ & $\bullet$ & $\bullet$ & $\bullet \bullet$ & $\bullet \bullet$ & $\bullet$ \\
$\bullet \bullet$ & $\cdots$ & $\bullet$ & $\cdots$ & $\bullet$ & $\bullet$ \\
$\bullet \bullet$ & $\cdots$ & $\cdots$ & $\cdots$ & $\cdots$ & $\cdots$ \\
$\begin{array}{r}\text { san } \\
3.4 .5 .6 .\end{array}$ & 1. & 1.2 & 3 & 4 & $a$ \\
& & & & &
\end{tabular}

Şekil 2. Braille Sayı Örnekleri (Özyürek, 1998)

Görme engelli bireyler için gündelik yaşamın bireyselleștirilmesi amacıyla büyütülmüș harflerden, körler için ise kabartmalı yazıdan yararlanılarak bireylerin kişisel farklılıklarına uygun ürünlere ve tasarımlara yer verilmektedir.

Görme yetersizliğinden etkilenmiş kişiler, sosyal yaşamlarını görme dişındaki dokunma, işitme, koklama gibi diğer duyulardan aldıkları referanslarla yürütmektedir. Dolayısıyla görme engelli bireylerin psikolojik boyutta doyum sağlamaları amacıyla, gündelik faaliyetlere etkin katılımlarını sağlayacak özelliklerde, bireyin engelini çağrıştıran giysilere karşı hassasiyetleri dikkate alınarak gerekli tasarımlar ve düzenlemeler geliștirilmelidir. Ancak bu şekilde toplum içerisinde firsat eşitliği sağlanarak engelli bireylerin toplumla bütünleşmesi gerçekleşecektir.

\subsection{Görme Engelli Bireylerin Giysi İhtiyaçları}

Görme engellilerin gündelik yaşamında karşı karşıya kaldıkları sorunlar oldukça fazladır. İşsiz olan, üretken kılınamayan, başkalarına bağımlı olmadan yaşayabilecek kapasiteye ulaşamayan engellilerin toplum içindeki gücü de yetersiz ve zayıf olmakta, toplumsal ilişkilerde eşit olma şansını elde edememelerine neden olmaktadır (Çarkçı, 2011). Bu durum aynı zamanda engelli bireyin toplumsal hayattan kopmasına, sosyal izolasyona yol açmaktadır. İhtiyaçlarını yeterince karşılayamayan engelli birey, toplumsal ilişkilere zaman ayıramadığı gibi kendisini toplumun bir parçası olarak da hissedememekte ve yalnızlaşmaktadır (Atıcı, 2007). $\mathrm{Bu}$ durum aynı zamanda kişinin psikolojisi üzerinde olumsuz etki yaratmaktadır.

Fiziksel koruma sağlamasının yanında, sosyal ve psikolojik açıdan da kişilerin yaşamlarını etkileyen giyim, büyük bir çoğunluğu giyinmelerini başkalarına bağımlı olarak gerçekleştiren engellilerin yaşamında da önemli rol oynamaktadır (Koca, 2007). Değișen ve gelişen dünyada her bireyin toplumla bütünleşmesi 
ve sosyal hayata katılması için yapılan tüm düzenlemelerin yanı sira bireyin giyinme becerilerinde de kendi kendilerine yeterli gelmeleri sağlanmalıdır. Bunun için bireylerin istek ve ihtiyaçları belirlenerek, herkes için tasarım ilkesinin dikkate alınması gerekmektedir.

Herkes için tasarım ilkesinin uygulanması teknoloji, hizmet sağlama ve ürün sektöründe engellilerin de dâhil olduğu geniş bir kullanıcı kitlesine uygun üretim yapma sonucunu doğurmaktadır. Ancak, daha geniş bir yelpazede üretim yapmak tüm engelli bireylere uygun ürünün yaplabilmesi anlamına gelmemektedir. $\mathrm{Bu}$ tip kullanıcıların ihtiyaçlarına erişimini sağlamanın en garantili yolu, onların özel ihtiyaçlarına göre üretim yapmak ya da ürünü engelli bireyin kullanacağı şekilde uyarlamaktır (Koca, 2007). Ancak bu șekilde bireyler arasındaki firsat eşitliği sağlanmış olacaktır.

Her sağlıklı insan kadar, kendini koruma ve kendi yaşamları hakkında seçim yapma hakkına sahip olan engelli kişilerin inancl ve toplumların bu konuda acıma duygularından sıyrılıp daha bilinçlenmeleri sayesinde, son zamanlarda engellilere yönelik ürün tasarımı daha çok dikkat ve ilgi kazanmaktadır (Schloss vd., 1994). Bunlar içerisinden Denizli Tekstil ve Hazır Giyimciler Derneği (DETGİS) Başkanı İsa Dal, görme engellilere yönelik hangi renkte tişört ve bornoz giydiklerini anlamaları için bir çalışma başlatmıştır. Bu çalışmada, görme engelliler için üretilen bornozların içerisine üretim esnasında meyve kapsülleri atılarak, giyen kişinin bornozun ne renk olduğunu koklayarak öğrenmesi sağlanmaktadır. Sarı renk için limon kokusu, turuncu için portakal kokusu, pembe için çilek kokusu vb. gibi koklama duyusu ile bornozun rengi anlatılmaya çalışılmış, tişörtlerin ön kısmında kullanılan İngilizce Braille alfabesi ile yazılmış renk isimleri de o tişörtün ne renk olduğu bilgisi dokunma duyusu ile bireye kazandırılmıştır.

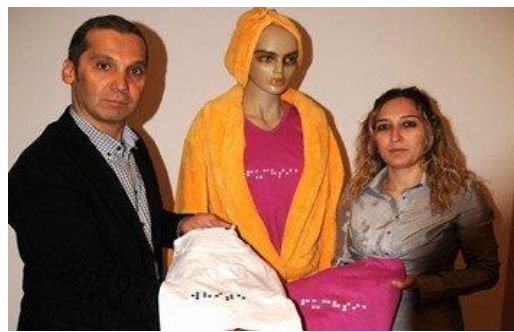

Şekil 3. Görme Engellilere Özel Tişört ve Bornoz (IHA, 2012).

Teknolojinin ve iyileştirme çalışmalarının artış göstermesi ile teknik tekstil sektörünün kullanım alanlarının genişletilmesi amacıyla düzenlenen İTHİB-ITTA Teknik Tekstil Proje Yarışması' nda görme engellilerin hayatını kolaylaştıran projede, giyim ve ev tekstili ürünlerinin etiketlerinin Braille alfabesiyle yazılmasından oluşmaktadır.

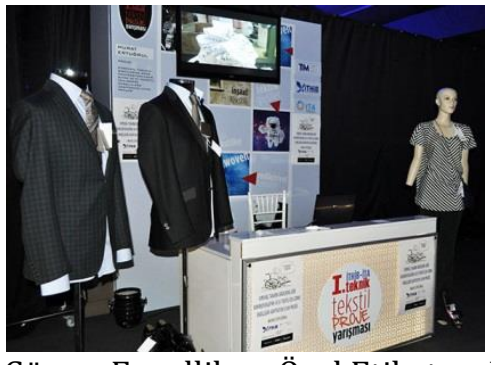

Şekil 4. Görme Engellilere Özel Etiket ve Kitapçık Tasarımı (Trtex, 2012).

Son yıllarda, engelli bireylerin yaşamlarını başkalarına ihtiyaç duymadan yürütebileceği, sosyal yaşama kolayca adapte olabileceği tasarımlar ve bu yönde araştırmalar hız kazanmaktadır. Ancak görme engelli bireyler için tasarlanan giysilerde Braille alfabesi baskısının ve giysilerin üretim maliyetinin yüksek olması firmaların yeterli desteği sağlayamamalarına sebep olmakta ve bu da halkın kişiye özel giysi ihtiyacını karşılayamamaktadır. Araştırmanın temelini oluşturan bu durum; üretim maliyetinin düşük tutularak engelli bireylerin düșük fiyatlı ve her yerde kolaylıkla ulaşabileceği kişiye özel giysilerin üretilmesi gerekliliği üzerinde durulmuştur.

\subsection{Görme Engelli Bireyler İçin Model Önerisi: Braille Alfabeli Giysiler}

Görme engelli bireylerin giysilerini satın alırken, giysi dolaplarından kıyafetlerini seçerken vb. gibi gündelik işlerini yerine getirmek için ikinci bir kişiye olan ihtiyacı ortadan kaldırmak amaçlı giysilere ihtiyaç duyulmaktadır. Bunun yanı sıra bireyin görme duyusu dışında kalan duyular yardımıyla giysilerinin renkleri, biçimleri, bedenleri gibi bilgileri öğrenmesi sağlanacak tasarımlar gerekmektedir. $\mathrm{Bu}$ durum dikkate alındığında, görme engelli kullanıcıların ihtiyaçlarına yönelik olarak tasarlanmış formlarda giysi üzerinde gerekli düzenleme ve eklemeler yapılmıştır. Bu giysiler engelli bireyin kendine güven duygusunu geliştirebileceği gibi, günlük yaşam aktivitelerini daha bağımsız yapabilmelerine olanak sağlamaktadır.

Giysiler üzerindeki bu gibi düzenlemelerin, düșük maliyetli olacağı düşüncesiyle elde işleme yapılabileceği gibi hazır giyim sektöründe de aynı yöntem kolaylıkla uygulanabilecektir. $\mathrm{Bu}$ fikirden hareketle görme engelli bireylerin bilgi edinmelerine yardımcı olabilecek Braille alfabesi, giysilerin yakalarının arka iç etiket kısmında, giysilerin etek uçlarında olabileceği gibi takıp çıkarılabilen bilgilendirme etiketleri de hazırlanarak bireyin sosyal yaşam içerisinde giysilerini satın alırken, giysi dolaplarından giysilerini arayıp bulmalarına yardımcı olacaktır. 


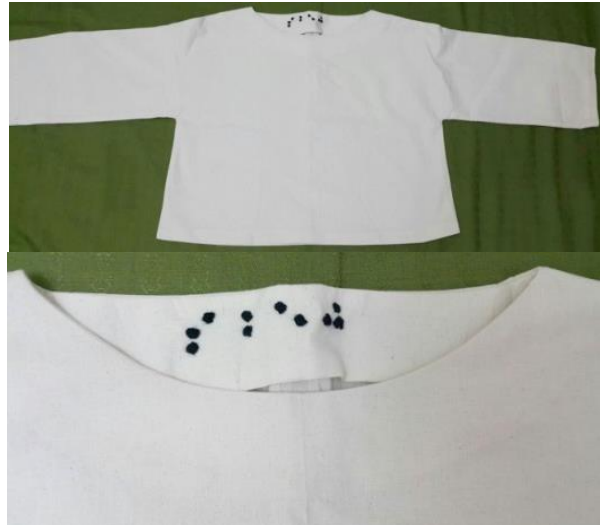

Şekil 5. Görme Engelli Kadın Tüketiciler İçin Tasarlanan Tişört Ve Braille Alfabesi İle Beden Ve Renk Bilgisi (S Bej)

Araștırma kapsamında hazırlanan kadın erkek için düz (basic) tişört etek ve tişört pantolondan oluşan 4 adet mini koleksiyondaki her bir giyside, öncelikle Braille alfabesinin işleneceği zemin işaretlenmiş sonrasında beden ve renk bilgisi alfabenin kurallarına uygun olarak siyah ip ile işlenmiștir. Bu şekilde birey, giysi satın alırken dokunma duyusu ile kendisine ait bedeni bulabilme imkânına erișecektir.

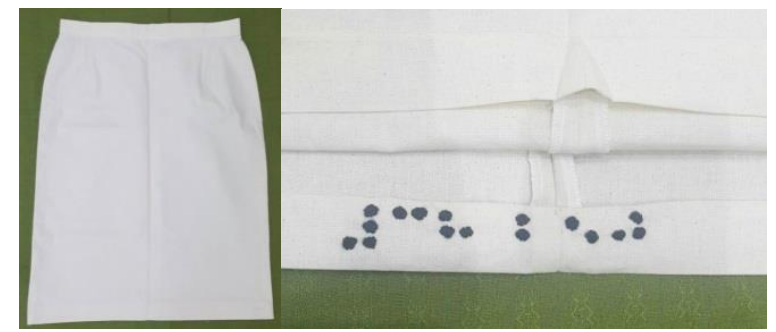

Şekil 6. Düz Dar Eteğin Etek Ucu Kısmında Braille Alfabesi İle Beden Ve Renk Bilgisi Önerisi (38 Bej)

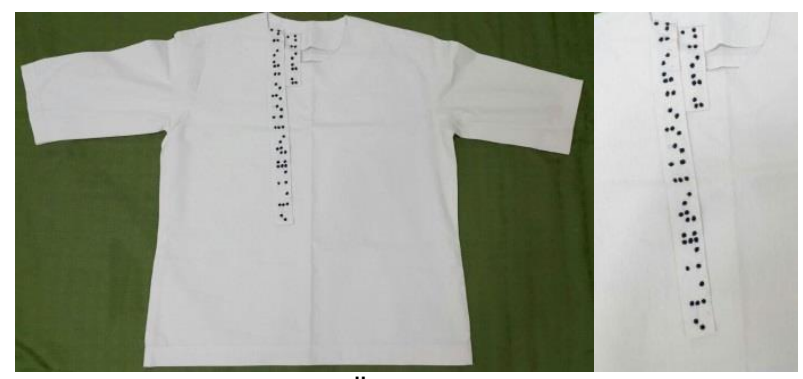

Şekil 7. Erkek Tişörtü Üzerine Tak-Çıkar Etiket ile Model, Renk Ve Beden Bilgisi Önerisi (Uzun Etiket: M Bej Bisiklet Yakalı Tişört) (Kısa Etiket: M Bej).

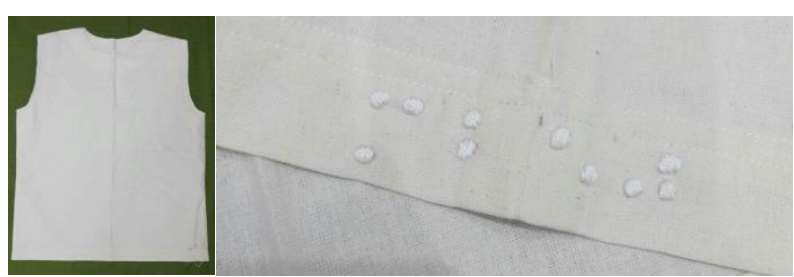

Şekil 8. Erkek Tişörtünün Etek Ucu Bölümüne Braille Alfabesi İle Beden Ve Renk Bilgisi (M Bej)

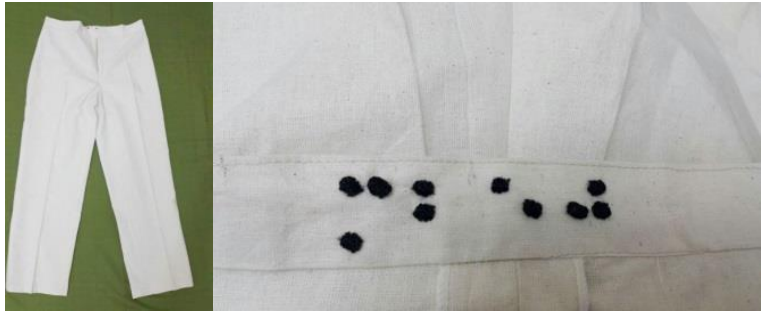

Şekil 9. Erkek Pantolonu Üzerine Braille Alfabesi İle Beden Ve Renk Bilgisi (M Bej)

\section{Materyal ve Yöntem}

$\mathrm{Bu}$ çalışmanın amacl, görme engelli bireylerin giysi temin ederken renklerini, modellerini ayırt edememeleri ve giysi dolaplarında kıyafetlerini bulma konusunda sıkıntı yaşamalarından yola çlkarak, bireylerin gündelik yaşamlarını kolaylaştırmak ve giysilerinin renklerini, modellerini vb. ayırt edebilecekleri tasarımlar ortaya koymaktır. Aynı zamanda hazır giyim sektöründe yetersiz olduğu düşünülen görme engelliler için giysi tasarımların gerekliliği ve öneminin kavratılarak bu konuda bir farkındalık kazandırılması amaçlanmıştır. Çalışmada öncelikli olarak bireylerin gündelik yaşamda yaşadıkları sıkıntılar araştırılmış ve bu sıkıntılarını gidermek için yapılan çalışmalar irdelenmiş ve bu doğrultuda yeni giysi önermeleri hazırlanmıştır.

Alan yazında ve projelerde görme engellilerin gündelik yaşamını kolaylaştırmak adına yapılan çalışmaların yeterli olmadığı düşüncesinden hareketle yapılan çalışmada; daha önce fikir ortaya konulmuş birçok çalıșmanın maliyet ve yetersiz destek gibi olumsuz yönleri giderilerek daha düşük bütçeli ve kişinin yakınlarının kendi evinde kolayca uygulayabileceği işleme yöntemi kullanılmıştır. Bu yöntem ile noktalar kabartmalar halinde işlenmiş dokunma duyusuna hitap edebilecek şekilde düzenlenmiştir. Birey parmağını kaldırma gereksinimi duymadan sadece hareket ettirerek giysi ile ilgili bilgi sahibi olması sağlanmıştır.

\section{Sonuç ve Tartışma}

Ülkemizde görme yetersizliğinden etkilenmiş birey ve bu bireylerin yakınları düşünüldüğünde ortaya çıkan sayı yadsınamayacak niceliktedir. Bu bağlamda engelli bireylerin gündelik yaşamlarını kolaylaştıracak ve çeşitli ihtiyaçlarını giderecek tasarımlara ve bu tasarımların yaygınlaștırılmasına ihtiyaç duyulmaktadır. Bireyler arasında fırsat eşitliği ilkesinin göz önünde bulundurularak herkes için tasarım ilkesinden hareketle tekstil ve hazır giyim ürünlerinde Braille alfabesinin kullanımıyla daha da zenginleştirilebilme olanağına sahiptir. Günümüz gerçekliğinde tasarımın, şuan herhangi bir engeli bulunmayan bireyler için olması gerektiği gibi kişinin hayatının herhangi bir evresinde engelli kalabileceği 
düşüncesi göz önünde bulundurularak ancak insan gereksinimleri sağlanmış olur. Türkiye' de hazır giyim sektörü, mağaza, vitrin vb. düzenlemeleri incelendiğinde görme engelli bireyleri kapsayan düzenlemelerin yetersiz olduğu ve giysi etiketlerindeki Braille alfabesinin yüksek maliyetli olması sebebiyle, tekstilde bu gibi düzenlemelere yer verilemediği ve girişimciler tarafından hazırlanan projelerin yine aynı sebeple uygulama safhasına geçirilemediği gözlenmiştir. $\mathrm{Bu}$ bağlamda, üretim maliyetlerinin düşünüldüğü bir sektörde rahatlıkla uygulanabilecek çeşitli öneriler geliştirilmiştir.

Görme yetersizliğinden etkilenen bireylerin gündelik yaşamlarını ikinci bir kişiye bağımlı olmadan sürdürebilmeleri ve bireyin sosyal yaşam içerisinde duygusal ve bilişsel motivasyonlarının arttırılmasına yönelik tasarımlara ihtiyaç duyulmaktadır. Engelli bireylerin gündelik yaşamlarının her alanında karşılaștıkları sorunların yanında, giysilerini satın alma veya giysi dolaplarından giysilerini arayıp bulmaları sırasında da aile bireylerine, genellikle de annelere bağımlı durumundadır. $\mathrm{Bu}$ bağımlılığı azaltmak amaçlı giysilere beden, renk ve model özelliği bilgisi işlenmiş, kullanıcının dokunarak bu bilgiye sahip olması sağlanmıştır. Öncelikle hazır giyim ürünleri arasından gündelik giysiler üzerine işlenmiştir. Ayrıca Braille alfabesi yordamıyla görme engelli bireylerin bilgiye ulașmasının sağlanabilmesi amaçlı hazır giyim ürünlerinin yanı sıra, aksesuar, mefruşat gibi ürünlere de bu bilgilerin işlenmesi gerekmektedir. $\mathrm{Bu}$ gibi ürünlerin yanı sıra ayakkabıların dil bölümünün iç kısmına bu harfler işlenerek bireyin sosyal yaşama uyumunda ona yardımcı olmak amaçlanmalıdır. Bir diğer önerme olarak hazırlanan tak-çıkar etiket önermesi ise genişletilerek farklı ürün gruplarında kullanıma uygun hale getirilebilmektedir.

Sosyal yaşama uyum sürecinde Braille alfabeli giysilerin, çağın teknolojisi ve sanatsal yönüyle birleştirilerek daha estetik ve daha işlevsel olacağl, tasarım fikrini daha anlamlı kılarak, geniş kitlelerde farkındalık uyandıracağı düşünülmektedir.

\section{Conflict of Interest / Çıkar Çatışması}

Yazarlar tarafından herhangi bir çıkar çatışması beyan edilmemiştir.

No conflict of interest was declared by the authors

\section{Teşekkür}

$\mathrm{Bu}$ çalışmanın yürütülmesinde fikirleriyle sonsuz destek veren Sayın Doç Dr. Emine Koca' ya ve yardımlarını esirgemeyen sevgili Öğr. Gör. Ş.Pınar Tunçok ve Öğr. Gör. Ayşin Çetinkaya' ya minnettarlıkla teșekkür ederiz.

\section{Kaynaklar}

Akçalı, Ş., 2015. Görme Engellilere Yönelik Tasarlanan Mekânların Erişilebilirlik Standartları Kapsamında İrdelenmesi: Görme Engelli Kütüphaneleri. Yüksek Lisans Tezi, Dokuz Eylül Üniversitesi, İzmir.

Arıkan, Ç., Sosyal model çerçevesinde özürlülüğe yaklaşım. Ufkun Ötesi Bilim Dergisi, 2,1, 11-25, (2002).

Atıcı, İ. Fiziksel Engelliler ve Kentsel Mekânın Kullanımı, Gazi Üniversitesi Sosyal Bilimler Enstitüsü, Ankara, (2007).

Çarkçı, Ş., 2011. Engellilerin mesleki eğitimi ve istihdamı. Yüksek Lisans Tezi, Marmara Üniversitesi, İstanbul.

Goldsmith, S.,1976. Designing for the disabled. London: Riba Publications,

Goltsman, S. M., Gilbert T. A. ve Wohlford, S. A., 1993. The Accessibility Checklist: An Evaluation System For Buildings And Outdoor Settings, California, Berkeley.

İHA (2012, Nisan 9) Görme engellilere özel tişört ve bornoz. $\quad 25 \quad$ Temmuz 2016. http://www.haberekspres.com.tr/gormeengellilere-ozel-tisort-ve-bornoz-h31590.html

Kanun 5378, 2005. Engelliler Hakkında Kanun. 21 Temmuz http://www.mevzuat.gov.tr/MevzuatMetin/1.5.5 378.pdf

Koca, E., 2007. Beyin Felçli (Serebral Palsi) Çocukların Giyinme Becerilerinde Giysiden Kaynaklanan Problemlerin Belirlenmesi ve Örnek Bir Uygulama. Doktora Tezi, Gazi Üniversitesi, Eğitim Bilimleri Enstitüsü, Ankara.

Özyürek, M., 1998. Görme Engelliler. Eskişehir, Anadolu Üniversitesi, Açık Öğretim Fakültesi.

Trammel, D. L., Schloss, P.J., \& Alper, S. 1994. Using Self-Recording, Evaluation, And Graphing To İncrease Completion Of Homework Assignments. Journal Of Learning Disabilities, 27, 75-81.

SGK, 2012. SGK Rehberi. 7 Şubat 2017, http://www.sgkrehberi.com/haber/11037/

Trtex., 2012. İthib Teknik Tekstil Proje Yarışması. 20 Kasim 2016, http://www.trtex.com/haberler/2841/ithibteknik-tekstil-proje-yarismasinda-birbirindenilginc-tekstil-tasarimlari-yaristi .

Türkiye İstatistik Kurumu (TÜİK)., 2010. Özürlülerin sorun ve beklentileri araştırması. 17 Temmuz 2016,

http://www.tuik.gov.tr/PreHaberBultenleri.do?id $=6370$ 